\title{
Experiments on Deposition Behavior of Fine Sediment IN A RESERVOIR
}

\author{
By Wei-Sheng Yu, ${ }^{1}$ Hong-Yuan Lee, ${ }^{2}$ and ShaoHua Marko Hsu ${ }^{3}$
}

\begin{abstract}
The deposition behavior of fine sediment is an important phenomenon, and yet it is unclear to engineers concerned about reservoir sedimentation. Laboratory experiments were conducted to produce both quasi-homogeneous flow and a turbidity current region divided by a plunge section. Silica powder (a noncohesive sediment) and kaolin (a cohesive sediment) were used as the suspended material. Because the effective gravitational force is the primary driving force for velocity in turbidity currents, the velocity profile was closely related to the concentration profile. The deposition rate of noncohesive coarser particles exponentially decays along the flow path. Most of the coarser particles were deposited in the quasi-homogeneous flow region or within a small distance downstream of the plunge section. The plunge did not carry those coarser particles further downstream. Deposition in the region of the turbidity current was found mainly by cohesive particles. Hydraulic sorting exists in the quasi-homogeneous flow region for noncohesive coarser particles, but becomes less significant in the downstream portion with deposition rates becoming mildly decayed. For fine cohesive particles, hydraulic sorting for the deposited gradation is not significant.
\end{abstract}

\section{INTRODUCTION}

Depending upon the sediment supply from the watershed and flow intensity in terms of velocity and turbulence, river flows usually carry sediment particles within a wide range of sizes. When a river flows into a reservoir, the coarser particles deposit gradually and form a delta in the headwater area of the reservoir that extends further into the reservoir as deposition continues (Fig. 1). Finer particles, being suspended, flow through the delta stream (Fig. 1) and pass the lip point of the delta, first entering a quasi-homogeneous (nonstratified) flow region and subsequently being deposited along the path due to a decrease in flow velocity caused by the increased crosssectional area. The region of quasi-homogeneous flow is shorter in cases of smaller discharge and/or higher sediment concentration. On the contrary, the region of quasi-homogeneous flow is longer in cases of larger discharge and/or lower sediment concentration. Until the section-averaged densimetric Froude number become about 0.6-1.0 (Lee and Yu 1997), the sediment-laden flow will plunge into the water body and move along the bed surface to form a turbidity current (or gravity current). The location of the plunge section can be easily identified in experiments by a distinct clear upper layer of ambient water against a turbid layer beneath the ambient water. A reverse flow, carrying suspended debris in the ambient upper layer, can also be observed. As it moves downward, the turbidity current can either deposit onto or erode the bed surface depending upon various factors.

For certain situations, the turbidity current, carrying silt and clay, can move for several tens of kilometers (Fan and Morris 1992). If the turbid inflow continuously flows into a reservoir, the turbidity current will sustain itself and arrive at the dam site. When it hits the dam, the turbidity current can soar up, and a muddy lake then forms. Fig. 1 is a schematic representation for a deposition delta, quasi-homogeneous flow region, turbidity current region, and a muddy lake. The deposition behavior in quasi-homogeneous flow region is not usually

\footnotetext{
${ }^{1}$ Assoc. Res. Sci., Environment Div., Agric. Engrg. Res. Ctr., Chungli 320, Taiwan.

${ }^{2}$ Prof., Dept. of Civ. Engrg., Nat. Taiwan Univ., Taipei, Taiwan.

${ }^{3}$ Assoc. Prof., Dept. of Hydr. Engrg., Feng Chia Univ., Taichung 407, Taiwan.

Note. Discussion open until May 1, 2001. To extend the closing date one month, a written request must be filed with the ASCE Manager of Journals. The manuscript for this paper was submitted for review and possible publication on February 25, 1999. This paper is part of the Journal of Hydraulic Engineering, Vol. 126, No. 12, December, 2000. (c)ASCE, ISSN 0733-9429/00/0012-0912-0920/\$8.00 + \$.50 per page. Paper No. 20418.
}

mentioned in the existing literature. The writers believe that a description of the entire deposition system is not complete without this portion. According to the above description, the deposition behavior of reservoir sediment relates closely to the size of the particles and flow patterns in the reservoir. Four categories of deposition can be distinguished: (1) Coarse-particle deposition in the delta; (2) fine-particle deposition in the quasi-homogeneous flow region; (3) finest-particle deposition in the turbidity current region; and (4) finest-particle deposition in the muddy lake region. Categories 2 and 3 are the focus of this paper.

In a pioneer experiment on turbidity current with a horizontal bed using plastic beads with a density of $1.52 \mathrm{~g} / \mathrm{cm}^{3}$ and a median particle size of $0.18 \mathrm{~mm}$, Middleton (1967) found that sorting exists in the longitudinal, vertical, and lateral directions. By creating turbidity currents inside a flume with a slope of 0.05 , Garcia (1985) observed that in most cases of his experiments, the coarsest portion of the sediment could not be kept in suspension and tended to settle down near the inlet region. In a series of experiments with a slope between 0 and 0.056 , using quartz flour with a median diameter of 0.014 and $0.032 \mathrm{~mm}$, Altinakar et al. (1990) found that the deposition effect slows down the marching velocity and increases the thickness of the head portion of the turbidity current. Garcia (1993) studied the transition process (hydraulic jump) between supercritical and subcritical turbidity currents, in which the bed slope was 0.08 for the supercritical portion and horizontal for the subcritical portion. In a case presented by Garcia (1993) involving a silica-laden flow (with a density of $2.65 \mathrm{~g} / \mathrm{cm}^{3}$ and a geometric mean of particles 0.004 and $0.009 \mathrm{~mm}$, respectively), the amount of deposition in the two portions did not show any significant difference. While in a case involving glass beads (with a density of $2.50 \mathrm{~g} / \mathrm{cm}^{3}$ and a geometric mean of particles 0.030 and $0.065 \mathrm{~mm}$, respectively) of a larger size, deposition begins at the inlet of the supercritical region and decays exponentially with the distance traveled.

The flow fields of turbidity current in the aforementioned literature were all controlled using sluice gates, and no plunge phenomenon occurred. In nature, however, plunge is an essential part in the whole system and cannot be overlooked. The effect of plunge upon the behavior of deposition in a reservoir is not clearly understood at present. Until now, only a few discussions have been conducted on the deposition of fine particles in a quasi-homogeneous flow region and the turbidity current region. The difference due to the cohesive effects between fine particles has not been discussed yet.

In this paper the experimental results cover both the quasi- 


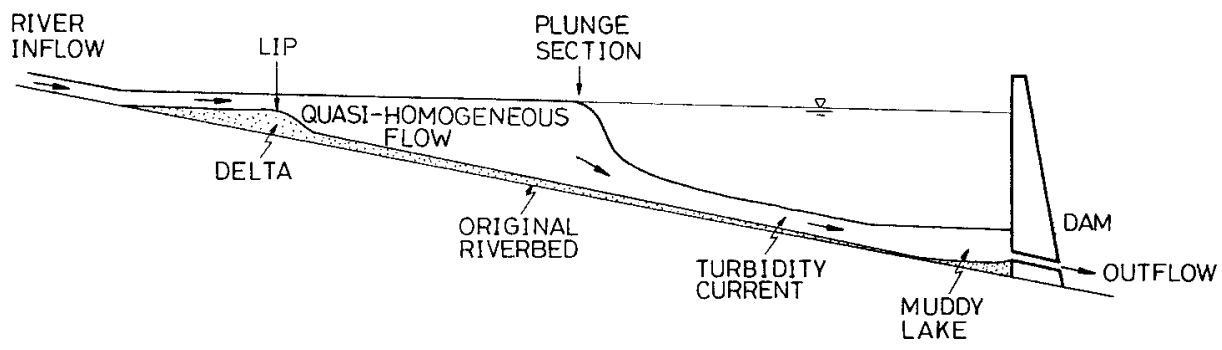

FIG. 1. Schematic Diagram for Flow Types of Sediment-Laden Water in Reservoir

homogeneous flow and the stratified turbidity current. Two types of sedimentary material were used: silica, a noncohesive material, and kaolin, a cohesive material. The topics focused upon are (1) comparison of the velocity and concentration profiles among the quasi-homogeneous flow, depositing turbidity current and nondepositing turbidity current; (2) the deposition process and gradation of cohesive or noncohesive deposited materials in the quasi-homogeneous flow region; (3) the deposition process and particle gradation of both cohesive and noncohesive material in the stratified turbidity-current region; and (4) comparison of the deposition amounts and gradation of the deposited materials between the upstream and downstream plunge sections.

\section{EXPERIMENTAL APPARATUS AND PROCEDURE}

Experiments were conducted in a transparent flume, 20-m long, 20-cm wide, and $60-\mathrm{cm}$ high, with a bottom slope of 0.02 . A cylindrical mixing tank with volume of $1.2 \mathrm{~m}^{3}$ was used for mixing sediment and water, which can supply all of the turbid-water inflow during one run.

Two head tanks, for clear water and turbid water, respectively, were installed. The turbid-water head tank has two concentric cylinders. The turbid water was pumped from the mixing tank to the inner tank of the turbid-water head tank. When the inner tank was full, the turbid water overflowed from the inner tank into the outer tank of the turbid-water head tank, and then the turbid water within the outer tank was quickly drained, by bottom valves, into the mixing tank. Mixers with a variable-speed motor were used in the inner tank of the turbid-water head tank and the mixing tank to keep the sediment in suspension. Turbid water was supplied into the flume, after the inner tank overflowed, by several near-bottom valves under the inner tank of the turbid-water head tank. A receiving tank was installed on the downstream end to detain the turbid water and drain it through an overflow weir and a bottom valve. The 20-m-long flume was divided into two parts. A 4-m-long section for the open channel region, and a 16-m-long section for the backwater region. The layout of the flume can be found in a work by Lee and Yu (1997).

A magnetic current meter, with an accuracy of $\pm 0.5 \mathrm{~cm} / \mathrm{s}$, was used to measure flow velocity. The diameter of the current meter is $0.9 \mathrm{~cm}$, and the length is $2.8 \mathrm{~cm}$. The magnetic field is interfered by the channel bottom and walls, and hence the current meters cannot be used in the near-wall region $(2 \mathrm{~cm}$ from the channel walls and $1 \mathrm{~cm}$ from the channel bottom). Siphon-type suction tubes with a diameter of $3.5 \mathrm{~mm}$ were used to take concentration samples. During the sampling process, the withdrawal velocity was set to be approximately equal to the flow velocity. An electronic balance with an accuracy of $0.0001 \mathrm{~g}$ was used to weigh the samples.

The suspended materials used were silica and kaolin with a specific gravity of 2.66 and 2.65 , respectively. The median particle diameter was 0.05 and $0.0068 \mathrm{~mm}$, respectively. The average particle fall velocities were 0.3950 and $0.0106 \mathrm{~cm} / \mathrm{s}$, respectively. Grain sizes larger than $0.074 \mathrm{~mm}$ (dimension of \#200 U.S. standard sieve) were measured using sieve analysis.

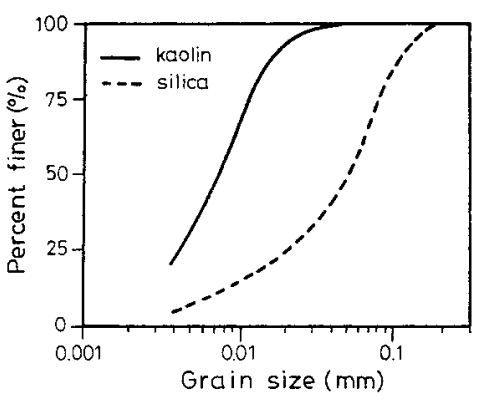

FIG. 2. Grain-Size Distribution Curves for Kaolin and Silt, Respectively

Grain sizes smaller than $0.074 \mathrm{~mm}$ were measured with a hydrometer. The particle-size distribution curves for the silica and kaolin are shown in Fig. 2.

Dispersion agent was added in part of the experimental runs to inhibit the cohesive effects between fine particles, according to the ASTM D 422 hydrometer analysis method for analyzing size distribution for particles below sieve \#200. For each 50 $\mathrm{g}$ of dry sample, a container with $200 \mathrm{~cm}^{3}$ of clear water should be used, and $1.5 \mathrm{~g}$ (or $3 \%$ ) of dispersion agent should be added, mixed uniformly, and soaked for $18 \mathrm{~h}$ before the experiment. In other words, the mass ratio for dry sample, water, and dispersion agent is 100:325:3. For each run, a sufficient amount of turbid water should be prepared in the mixing tank for the whole run such that the concentration of the turbid water can be constant.

To begin the experiment, the flume was first filled with clear water to form a reservoir, and then turbid water was released from the head tank. The outflow discharge was set equal to the inflow discharge. The inflow discharge and its sediment concentration were kept constant during each experimental process.

Three groups of experiments were conducted. The experimental conditions for these groups are listed in Table 1, in which $q_{i}$ is the inflow discharge per unit width; $\bar{C}_{i}$, dimensionless by volume, is the inflow concentration of the suspended material; and $T$ is the water temperature. All runs were depositing processes without erosion. Case A was designed to investigate the deposition behavior of silica in a quasi-homogeneous flow region. Case $\mathrm{B}$ investigated the deposition behavior of kaolin in a quasi-homogeneous flow region and a turbidity current region. Case $\mathrm{C}$ was conducted to investigate the difference in deposition between the upstream and downstream plunge sections. A dispersing agent, sodium hexametaphosphate, was added in all Case A runs as noncohesive behavior was being studied. For the same reason, a dispersing agent was also added in the three runs of Case C. In Cases B and $\mathrm{C}$, quasi-homogeneous flow and turbidity current coexisted in each experiment. In Case A, the discharge and concentration were controlled to inhibit the occurrence of plunge. In all runs, the inflow discharge and inflow sediment concentration were recorded. The velocity of the marching head of the turbidity current was measured for calculating the depo- 
TABLE 1. Experimental Conditions for All Cases

\begin{tabular}{|c|c|c|c|c|c|c|c|c|}
\hline $\begin{array}{l}\text { Case } \\
(1)\end{array}$ & $\begin{array}{l}\text { Flow type } \\
\text { (2) }\end{array}$ & $\begin{array}{l}\text { Suspended } \\
\text { materials } \\
\text { (3) }\end{array}$ & $\begin{array}{l}\text { Run } \\
\text { number } \\
\text { (4) }\end{array}$ & $\begin{array}{l}\text { With } \\
\text { dispersing } \\
\text { agent } \\
\text { (5) }\end{array}$ & $\begin{array}{c}q_{i} \\
\left(\mathrm{~cm}^{2} / \mathrm{s}\right) \\
(6)\end{array}$ & $\begin{array}{c}\bar{C}_{i} \\
\text { (dimensionless } \\
\text { by volume) } \\
(7)\end{array}$ & $\begin{array}{l}\text { Total sediment } \\
\text { added in } \\
\text { mixing tank } \\
\text { (8) }\end{array}$ & $\begin{array}{l}\mathrm{T} \\
(9)\end{array}$ \\
\hline \multirow[t]{4}{*}{ A } & \multirow[t]{4}{*}{ Quasi-homogeneous flow } & \multirow[t]{4}{*}{ Silica } & HS 1 & $\sqrt{ }$ & 138.410 & 0.00185 & - & 23.2 \\
\hline & & & HS2 & $\checkmark$ & 138.740 & 0.00083 & - & 23.4 \\
\hline & & & HS3 & $\checkmark$ & 167.131 & 0.00170 & - & 23.4 \\
\hline & & & HS4 & $\checkmark$ & 259.771 & 0.00373 & - & 22.0 \\
\hline \multirow[t]{2}{*}{ B } & \multirow{2}{*}{$\begin{array}{l}\text { Both quasi-homogeneous } \\
\text { flow and turbidity cur- } \\
\text { rent }\end{array}$} & \multirow[t]{2}{*}{ Kaolin } & HK1 & $\mathrm{X}$ & 101.358 & 0.00144 & - & 18.0 \\
\hline & & & HK2 & $\mathrm{X}$ & 208.454 & 0.00324 & - & 19.8 \\
\hline \multirow[t]{4}{*}{$\mathrm{C}$} & \multirow{4}{*}{$\begin{array}{l}\text { Both quasi-homogeneous } \\
\text { flow and turbidity cur- } \\
\text { rent }\end{array}$} & \multirow{4}{*}{$\begin{array}{l}\text { Both silica and } \\
\text { kaolin }\end{array}$} & TP1 & $\checkmark$ & 68.989 & 0.00512 & 20-kg silica & 20.4 \\
\hline & & & TP2 & $\sqrt{ }$ & 68.263 & 0.00748 & $\begin{array}{l}\text { 20-kg silica } \\
10-\mathrm{kg} \text { kaolin }\end{array}$ & 21.0 \\
\hline & & & TP3 & $\mathrm{X}$ & 68.653 & 0.00748 & 20-kg silica & 20.8 \\
\hline & & & TP4 & $\sqrt{ }$ & 68.842 & 0.01596 & $\begin{array}{l}\text { 20-kg silica } \\
50-\mathrm{kg} \text { kaolin }\end{array}$ & 21.3 \\
\hline
\end{tabular}

sition time interval only on each sampling reach along the flow path. The velocity and concentration profiles were measured in some of the other runs, and the experimental conditions for those runs are not shown in Table 1. After each run was completed, the water in the flume was drained slowly, and the amount and gradation of the deposition along the distance was measured.

\section{RESULTS AND ANALYSIS}

\section{Velocity and Concentration Profiles}

\section{Quasi-Homogeneous Flow}

The velocity and concentration profiles for the quasihomogeneous flow are similar to the open-channel flow profiles, in which the larger the Rouse number, $W_{s} / \kappa U_{*}$ (where $W_{s}$ is fall velocity of the suspended sediment; $\kappa$ is the von Kármán constant, and $U_{*}$ is shear velocity), the more nonuniform the concentration profile and the suspended sediments tend to concentrate toward the channel bed. For the experiments in Case A, the quasi-homogeneous flow with silica suspension deposition occurred along the entire flume. In the upstream portion, the rate of deposition was significant, and therefore the concentration near the bed was large. Toward the downstream portion, the size of the suspended particles became finer due to the lack of coarse particles. The rate of deposition slowed down, and the concentration profile became more uniform, vertically. The typical concentration profiles for the quasi-homogeneous flow are shown in Fig. 3, in which $X$ is the distance form the flume entrance; and $H$ is the water depth.

\section{Turbidity Current}

In the stratified flow, the kaolin turbidity current without a dispersing agent was deposited along the flow path due to its flocculation behavior. The velocity and concentration profiles in this deposition case are shown in Fig. 4, in which $U, C$, and $\mathrm{Ri}_{g}$ are the velocity, concentration, and gradient Richardson number [definition referred to in (1)] at a local position, respectively; and $Z$ is the vertical distance, normal to the bed, from the channel bed. On the contrary, kaolin with a dispersing agent (sodium hexametaphosphate) was not deposited. The velocity and concentration profiles for this nondeposition case are shown in Fig. 5. The difference between the profiles in Figs. 4 and 5 are obvious. The concentration profile gradient at the lower portion of the deposition case (Fig. 4) shows a highly nonuniform concentration with an increase near the bed. The corresponding velocity profile is also different from that of a normal open-channel flow. The high concentration

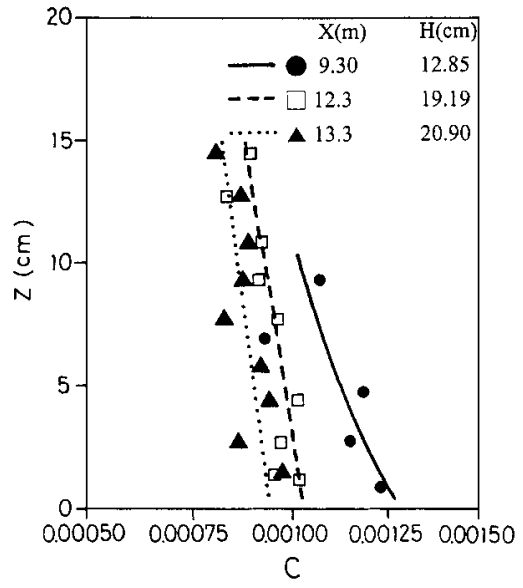

FIG. 3. Typical Concentration Profiles for Quasi-Homogeneous Flow

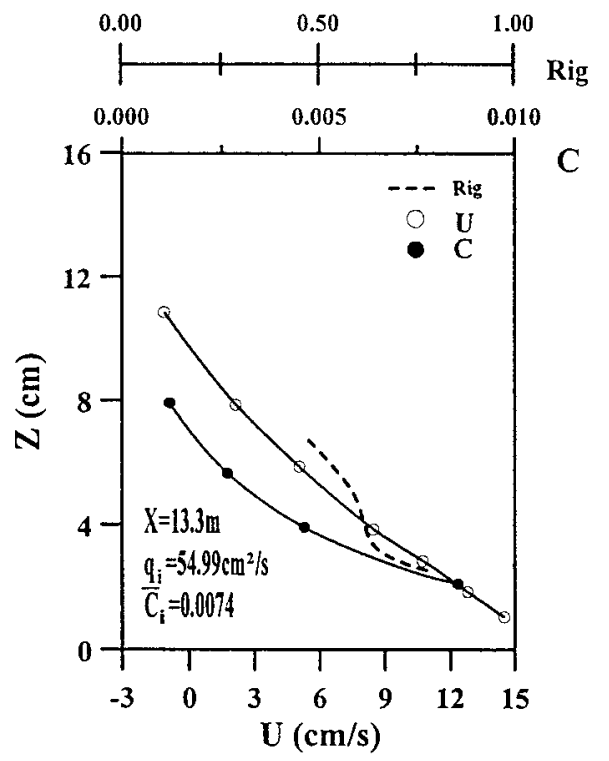

FIG. 4. Typical Velocity and Concentration Profiles of Deposited Turbidity Current

near the bed in Fig. 4 indicates an increase in the effective gravitational force quantified as $g(s-1) C \sin \theta \Delta Z$, where $g$ is the gravitational acceleration; $s$ is the specific gravity of suspended solid; $\theta$ is the angle of the bed slope; and $\Delta Z$ is an element in the vertical direction, the gravitation term of the momentum equation for the turbidity current (Yu and Lee 


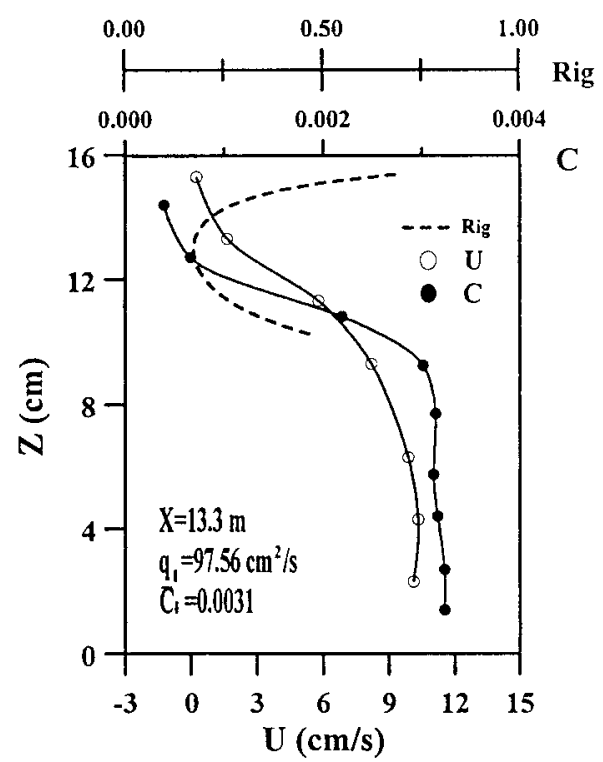

FIG. 5. Typical Velocity and Concentration Profiles of Turbidity Current with Dispersing Agent

1993), increasing the velocity near the bed. This is a clear distinction between a stratified flow and an open-channel flow. In an open-channel flow, the velocity profile is not dominated by the concentration distribution. In addition, the lower portion of the concentration profile in the nondeposition case (Fig. 5) is nearly constant and is similar to that in an open-channel flow with a wash load. The velocity profile of the lower layer in Fig. 5 is also similar to that in an open-channel flow.

In a stratified flow, the gradient Richardson number is usually a good indicator of the degree of unstableness at a local point. The definition of the gradient Richardson number is as follows:

$$
\mathrm{Ri}_{g}=-\frac{g \frac{d \rho_{m}}{d z}}{\rho_{m}\left(\frac{d U}{d z}\right)^{2}} \cos \theta
$$

in which $\rho_{m}=$ density of a point with a specified $Z$ value; $\rho_{m}$ is equal to $\rho_{s} C+\rho_{a}\left(1-C\right.$ ) (where $\rho_{s}$ and $\rho_{a}$ are the densities of the suspended sediment and ambient fluid), respectively; $\mathrm{Ri}_{g}$ is always positive. It is found that the larger the velocity gradient $d U / d Z$, the smaller the $\mathrm{Ri}_{g}$ becomes, which indicates greater instability and more local mixing. In Garcia's supercritical flow experiments (Garcia 1993), the averaged value for $\mathrm{Ri}_{g}$ is 0.16 at the interface between the ambient fluid and the turbidity current, whereas, in the subcritical case, the similar value is 0.64 . Garcia inferred that for $\mathrm{Ri}_{g}$ values approximately larger than 0.25 , turbulence cannot be maintained against stable stratification. He illustrated that his subcritical flows are stable, and mixing at the interface is negligible.

In Fig. 4 (the deposition case of turbidity current), the $\mathrm{Ri}_{g}$ values are between 0.46 and 0.78 , which are all larger than 0.25 . From Garcia's inference as mentioned before, this indicates a stable condition in the deposition case, in which mixing between the clear and turbid water at the interface can be disregarded. In Fig. 5 (the case without deposition), the velocity and concentration decrease rapidly at the position above $Z=$ $9 \mathrm{~cm}$, at which the interface divides the turbidity current layer, and are obviously different as compared with the deposition case in Fig. 4.

Based on (1), which is the definition of $R i_{g}$, point values of $\mathrm{Ri}_{g}$ rely on the accuracy of the gradients for $d C / d Z$ and $d U / d Z$ at each point. It is found that it is better to rely on the fitted curve of $C(\mathrm{Z})$ and $U(Z)$ rather than measured point values of $C$ and $U$ to obtain the gradients.

Eighteen runs of kaolin turbidity current with dispersing agent in a study by Lee and Yu (1997) showed that the similarity collapse is good for the velocity and concentration profiles, and those can be fitted to (2) and (3), respectively

$$
\begin{gathered}
\frac{U}{\bar{U}}=1.15(3 \eta)^{0.05}, \quad 0 \leq \eta \leq \frac{1}{3} \\
\frac{U}{\bar{U}}=1.15 \exp \left[-7.7\left(\eta-\frac{1}{3}\right)^{4}\right], \quad \frac{1}{3} \leq \eta \leq 1.3 \\
\frac{C}{\bar{C}}=1.15, \quad 0 \leq \eta \leq 0.6 \\
\frac{C}{\bar{C}}=1.15 e^{-15.43(\eta-0.6)^{2}}, \quad 0.6 \leq \eta \leq 1.3
\end{gathered}
$$

where $\eta=Z / h$, in which $h$ is the calculated thickness of turbidity current. The turbidity current thickness, layer-averaged velocity, and layer-averaged concentration can be calculated from the measured velocity profile as follows (Ellison and Turner 1959, Parker et al. 1987):

$$
\begin{gathered}
h=\frac{\int_{0}^{\delta} U d z}{\bar{U}} \\
\bar{U}=\frac{\int_{0}^{\delta} U^{2} d z}{\int_{0}^{\delta} U d z} \\
\bar{C}=\frac{\int_{0}^{\delta} C U d z}{\int_{0}^{\delta} U d z}
\end{gathered}
$$

in which $\delta=$ distance between the channel bed and the position where the velocity equals zero; $\bar{U}=$ layer-averaged turbidity current velocity; and $\bar{C}=$ layer-averaged turbidity current concentration.

The bulk Richardson number Ri (Ellison and Turner 1959) can be defined as follows:

$$
\mathrm{Ri}=\frac{g(s-1) \cos \theta \bar{C} h}{\bar{U}^{2}}
$$

Based on (1) and (5), the relationship between $\mathrm{Ri}_{g}$ and $\mathrm{Ri}$ is as follows:

$$
\mathrm{Ri}_{g}=F(\eta) \times \mathrm{Ri}
$$

where $F(\eta)=$ function for the shape of gradient Richardson number

$$
F(\eta)=-\frac{\frac{d(C / \bar{C})}{d(Z / h)}}{\left[\frac{d(U / \bar{U})}{d(Z / h)}\right]^{2}}
$$

Turner (1973) discussed the relationship between $\mathrm{Ri}_{g}$ and $\mathrm{Ri}$ for several special circumstances. In this study, $F(\eta)$ can be specified based on the measured data. Selecting the zone across the interface $(\eta \approx 1)$ and substituting $(2 b)$ and $(3 b)$ into (7), one can obtain 


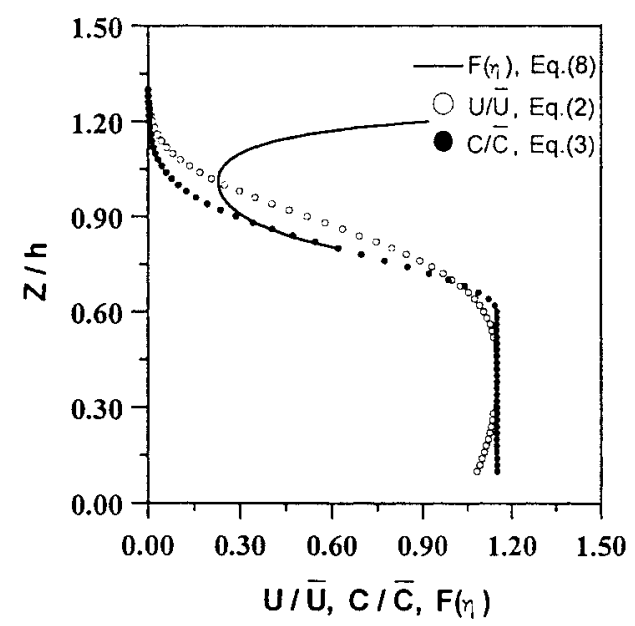

FIG. 6. Dimensionless Velocity, Concentration, and $F(\eta)$ Profiles of Turbidity Current with Dispersing Agent

$$
F(\eta)=\frac{1}{35.3511} \frac{(\eta-0.6)}{(\eta-0.3333)^{6}} e^{\alpha}
$$

where $\alpha=-15.43(\eta-0.6)^{2}+15.4(\eta-0.3333)^{4}$. Eqs. $(2 a),(2 b),(3 a),(3 b)$, and (8) are plotted in Fig. 6. The derivative of (8) is taken as follows:

$$
\begin{aligned}
& \frac{d F(\eta)}{d \eta}=\frac{1}{35.3511} \frac{1}{(\eta-0.3333)^{7}} \\
& \cdot\left(61.6 \eta^{5}-119.1 \eta^{4}+59.5 \eta^{3}+13.6 \eta^{2}-22.2 \eta+6.5\right) e^{\alpha}
\end{aligned}
$$

The minimum value of $\mathrm{Ri}_{g}$ can be found as $\eta=1.01$ by solving (9) with $\eta$ ranging between 0.6 and 1.2. This shows that the thickness of the turbidity current calculated by the velocity profile [(4)] is exactly at the position of the minimum $\mathrm{Ri}_{g}$ value, in which the instability is maximum and the mixing is nonnegligible. Hence, $\eta=1$ can be used as a criterion to define the interface.

For the case of Fig. 5, the calculated thickness $h$ is 12.8 $\mathrm{cm}$; layer-averaged velocity $\bar{U}$ is $8.93 \mathrm{~cm} / \mathrm{s}$; and layer-averaged concentration $\bar{C}$ in a dimensionless form by volume is 0.00291 (Lee and Yu 1997). Taking $g=980 \mathrm{~cm}^{2} / \mathrm{s}, s=12.65$, and cos $\theta \approx 1$, then substituting the above values of $h, \bar{U}$, and $\bar{C}$ into (5), the calculated $\mathrm{Ri}$ value for the case of Fig. 5 is 0.76 . Substituting the Ri value and the $F(\eta)$ of (8) into (6), one can obtain the profile of $\mathrm{Ri}_{g}$ at the region across the interface $(\eta \approx 1)$ for the case of Fig. 5. The calculated $R i_{g}$ is plotted on Fig. 5, and the $\mathrm{Ri}_{g}$ value is 0.17 at the interface. Because the $\mathrm{Ri}_{g}$ value is smaller than 0.25 , the mixing effect is not negligible at the interface in the nondeposition case of turbidity current.

\section{Deposition Rate}

\section{Definition of Deposition Rate}

The deposition rate, $W_{D}$, is the rate of the bed-elevation increase within each flume reach without considering the porosity effect and can be calculated using the measured data as follows:

$$
W_{D}=\frac{\Delta W}{\gamma_{s} B \Delta x \Delta t}
$$

where $\gamma=$ specific weight of the sediment; $B=$ width of the flume; and $\Delta W=$ weight of the deposited sediment within the sampled segment $\Delta X$ in the time interval $\Delta t$. The quantities on the right-hand side of (10) are all measurable. The depo- sition rate for each size fraction can be obtained by multiplying (10) by the measured gradation of the deposited sediment.

\section{Quasi-Homogeneous Flow}

The quasi-homogeneous flow is between the downstream end of the deposition delta and the plunge section. Because the formation of a delta may take a long time, all of the experiments in Case A were terminated before a delta could be formed. A typical profile of the deposition rate for silica (Run HS4) is shown in Fig. 7, in which a peak value exists at $X=$ $8.5 \mathrm{~m}$ and exponentially decays after the peak. The $D_{50}$ in Fig. 7 refers to the median diameters of deposited particles. In Fig. 7. the location of the peak deposition rate is $2 \mathrm{~m}$ downstream of the starting point of the backwater region. After the starting point, the deposition rate increased downward until the deposition-rate peak occurred. If sufficient time is permitted, a delta will gradually form between the starting point and the point of peak deposition rate (Yu et al. 2000). As a consequence, the effective sampling location for the quasi-homogeneous flow is downstream of the peak. In Fig. 7, the deposition rate of quasi-homogeneous flow decays from 0.00107 to $0.00016 \mathrm{~cm} / \mathrm{s}$ within a length of $8.9 \mathrm{~m}$.

Fig. 8 compares the deposition pattern between cohesive

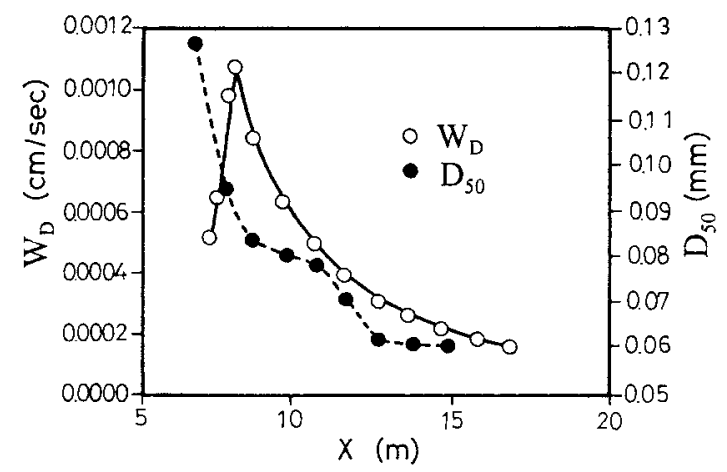

FIG. 7. Deposition Rate and Median Diameter with Distance of Deposited Sediment (Run HS4)

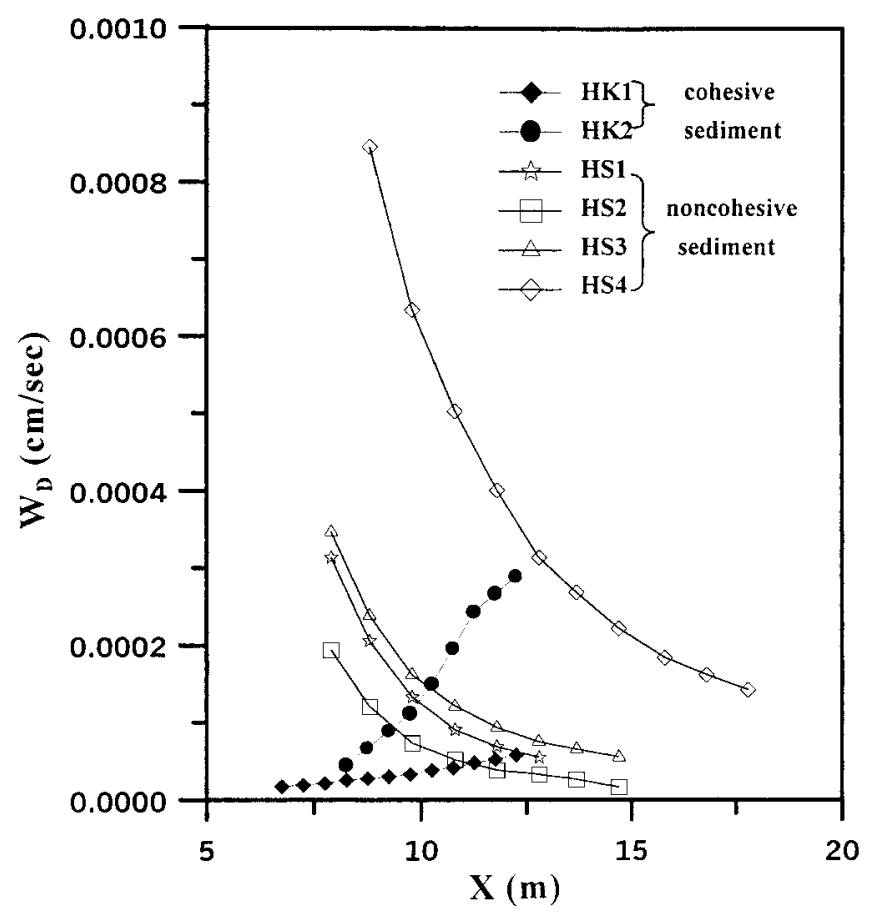

FIG. 8. Comparison of Deposition Patterns between Silica (Noncohesive) and Kaolin (Cohesive) Suspension in QuasiHomogeneous Flow Region 
and noncohesive suspended sediments. The deposition rate for noncohesive material decays exponentially along the path as previously stated. On the contrary, the deposition rate for cohesive material increases along the path. The behavior of noncohesive material is similar to cases of particle transportation without resuspension, which usually occurs in a settling basin (Camp 1946). Sumer (1977) also stated that the distribution of deposited particles follows an exponential decay function along the flowing path of a settling basin. The deposition of cohesive materials is due to the flocculation behavior between the sediment particles. As flow intensity decreases toward the downstream direction, the cohesive effect becomes relatively strong.

\section{Plunge Effect on Deposition of Noncohesive Sediment}

In the homogeneous flow region, the deposition rate for noncohesive sediment follows an exponential decay as previously stated. Under certain conditions, a plume occurs, and then a turbidity current forms. Runs TP1, TP2, and TP4 of Case $\mathrm{C}$ are cases for noncohesive suspended sediment. In these three runs, $20 \mathrm{~kg}$ of silica was used, but different amounts of kaolin were added. All of the sediment was added into the mixing tank and mixed with clear water using a variable speed motor. The sediment was kept suspended in the mixing tank, so that the inflow sediment concentration could be kept constant during each run. Run TP1 used no kaolin; Run TP2 used $10 \mathrm{~kg}$ of kaolin; and Run TP4 used $50 \mathrm{~kg}$. In all three runs, a dispersing agent was used to eliminate the cohesive effects. From Lee and Yu (1997), the plunge criteria can be expressed as follows:

$$
H_{p}=\beta \cdot\left(\frac{q_{p}^{2}}{g_{p}^{\prime}}\right)^{1 / 3}
$$

where $H_{p}=$ water depth; $\beta=$ coefficient; $q_{p}=$ discharge per unit width; $g_{p}^{\prime}=$ effective gravitational acceleration; $g_{p}^{\prime}=$ $g(s-1) \bar{C}_{p}$; and $\bar{C}_{p}=$ cross-sectional-averaged concentration of the suspended sediment. The subscript $p$ is just an index of the plunge section. Based on field and flume data, most researcher found that the B value was between 1.0 and 1.4 (Lee and Yu 1997), except for Wunderlich and Elder (1973), whose $\beta$ is 1.6. Based on flume experiments, Lee and Yu (1997) stated that the downstream stage would affect the $\beta$ value and make it larger than 1.4. Other factors are unsteady flow and reservoir geometry, as well as other minor factors. Based on the above statement, (11) could be used to approximately estimate the plunging depth, even in the field.

From (11), the location of the plunge section is obviously affected by the concentration. The higher the concentration, the earlier the plunge occurs. For Runs TP1, TP2, and TP4, the plunge section occurs at $X=10.1,8.6$, and $7.2 \mathrm{~m}$, respectively. How the deposition behavior changes from the plunge section is shown in Fig. 9, in which the variation of deposition rates along the longitudinal direction of Case $\mathrm{C}$ are plotted. Fig. 9 indicates that the location of plunge has no affect upon the trend of deposition rate in the streamwise direction since each curve is smooth across its plunge section.

The peak value of the deposition rate for Run TP4 was the largest among these three runs because it possessed the greatest amount of coarser particles. Fig. 9 indicates that the plunge did not carry those coarser particles further downstream. Most of the coarser particles were deposited in the quasi-homogeneous flow region or within a small distance downstream of the plunge section. This explains why in Garcia's experiments $(1985,1993)$, in which turbidity currents were created by a submerged gate without a plunging process, the coarser particles all deposited near the entrance and decayed exponentially.

\section{Plunge Effect on Deposition of Cohesive Sediment}

In the homogeneous flow region, the deposition rate of the cohesive sediment increased along the path as stated before. The effect of the plunge section upon the cohesive sediment deposition is also shown in Fig. 9. Run TP3 is the only run in Case $\mathrm{C}$ in which no dispersing agent was added. As a result, the deposition rate for Run TP3 uniquely increased after the plunge section. In cases of turbidity currents without a dispersing agent, the deposition after the plunge section, $X=9.5$ $\mathrm{m}$, was dominated by cohesive particles, and the deposition increased downstream. This is similar to the experiments in Case B.

Fig. 10 shows the deposition rate for Case B (with kaolin only) as well as the location of the plunge section. Although the deposition increased all the way downstream, the gradient of the deposition rate slowed down after the plunge section. This indicates that the decay of the flow intensity in a stratified flow case is mild compared to that in a quasi-homogeneous flow.

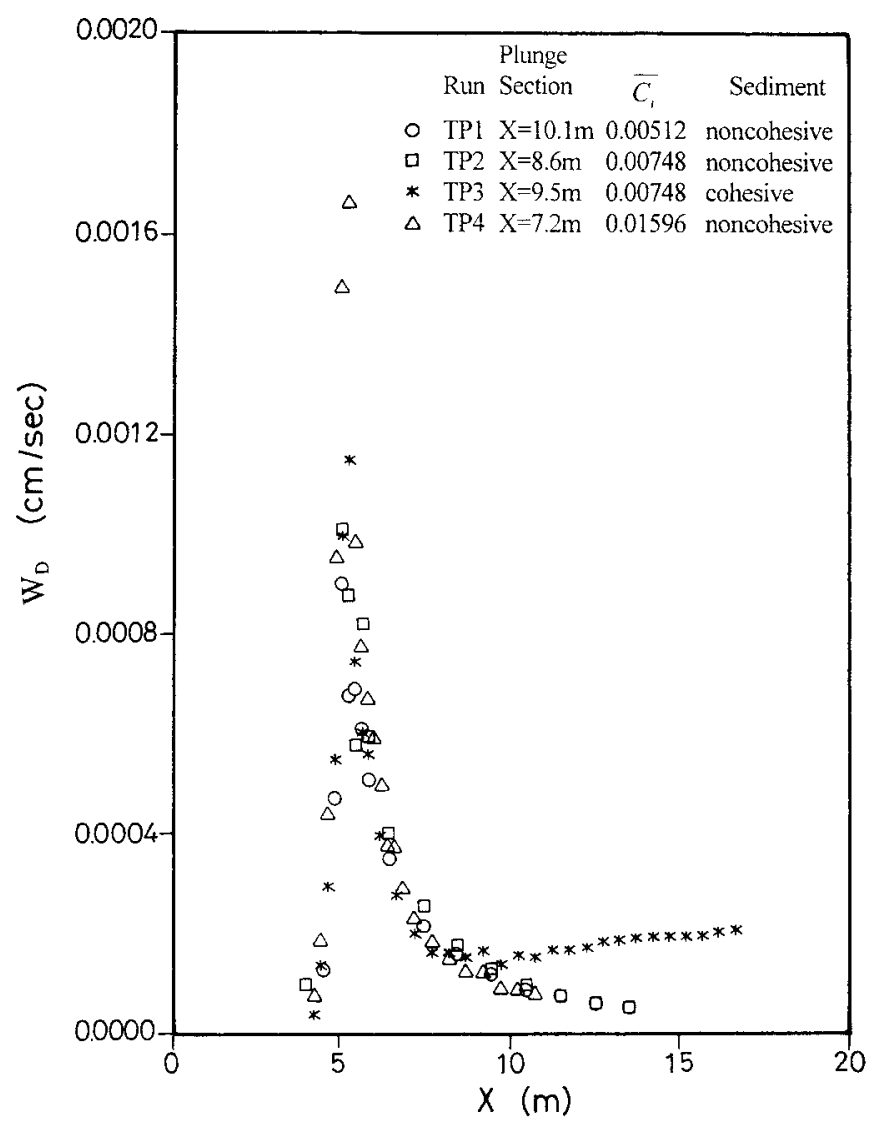

FIG. 9. Deposition Rate along Flow Distance in Case C

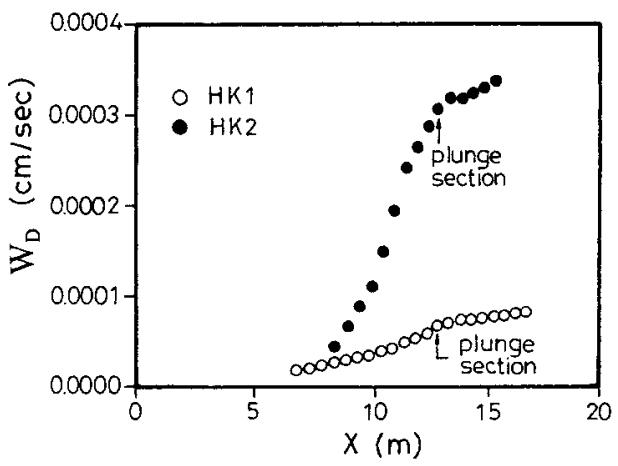

FIG. 10. Deposition Rate along Flow Distance in Case B 


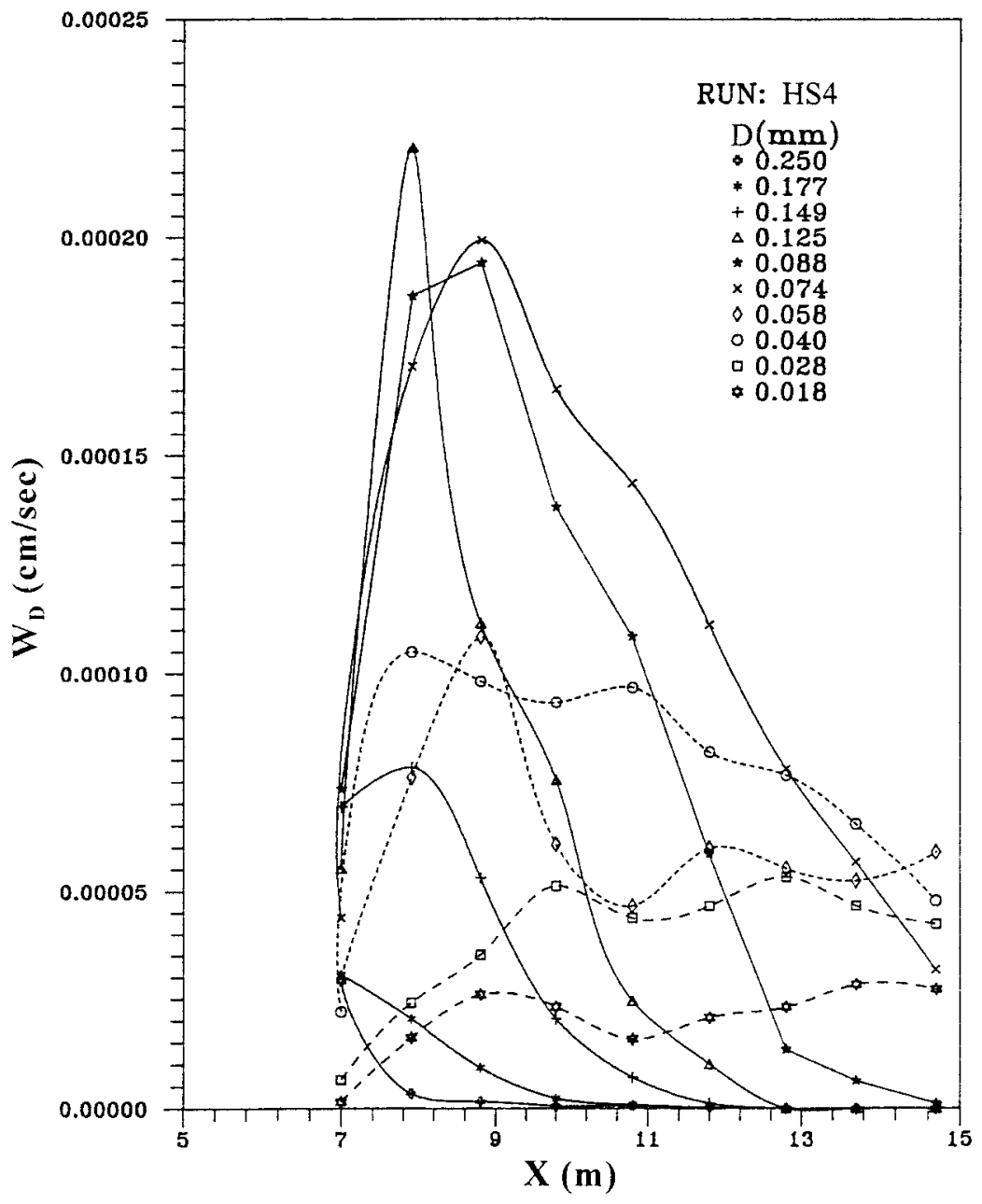

FIG. 11. Deposition Rate along Flow Distance for Each Size Fraction in Run HS4

TABLE 2. Profile of Median Diameters and Geometric Standard Deviations of Deposited Sediment at Different Locations

\begin{tabular}{c|c|c|c}
\hline \hline \multirow{3}{*}{$\begin{array}{c}X u n \\
(1)\end{array}$} & $\begin{array}{c}X \\
(\mathrm{~m})\end{array}$ & $\begin{array}{c}D_{50} \\
(\mathrm{~mm})\end{array}$ & $\sigma_{g}$ \\
\hline HS4 & $(2)$ & $(3)$ & $(4)$ \\
\hline & 0.0 & 0.052 & 3.03 \\
& 6.8 & 0.127 & 1.57 \\
& 7.8 & 0.095 & 1.59 \\
& 8.8 & 0.084 & 1.59 \\
& 9.8 & 0.081 & 1.73 \\
& 10.8 & 0.079 & 1.58 \\
& 11.8 & 0.071 & 1.55 \\
HK1 & 12.8 & 0.062 & 1.55 \\
& 13.8 & 0.061 & 1.61 \\
& 14.8 & 0.061 & 1.61 \\
& 0.0 & 0.0068 & - \\
& 7.3 & 0.0059 & - \\
& 8.3 & 0.0054 & - \\
& 9.3 & 0.0057 & - \\
& 10.3 & 0.0051 & - \\
& 11.3 & 0.0060 & - \\
& 12.3 & 0.0057 & - \\
& 13.3 & 0.0054 & 4.07 \\
& 14.3 & 0.0063 & 1.63 \\
& 15.3 & 0.0057 & 1.76 \\
& 0.0 & 0.02 & 1.75 \\
& 6.5 & 0.069 & 2.14 \\
& 7.5 & 0.053 & 2.10 \\
\hline \hline
\end{tabular}

\section{Size Gradation of Deposition}

Noncohesive Sediment in Quasi-Homogeneous Flow

In Fig. 7 , the median diameters, $D_{50}$, of deposited particles in Run HS4 are also plotted against $W_{D}$ with respect to the longitudinal direction. It can be observed in Fig. 7 that hydraulic sorting is more significant in the region with increasing $W_{D}$. The trend in $D_{50}$ shows that hydraulic sorting exists in the $W_{D}$ decreasing region, but it is no longer that obvious in the downstream reaches. In the region downstream of $X=12.8$ $\mathrm{m}$, hydraulic sorting becomes weak and so is the $W_{D}$ decay.

In Fig. 11, $W_{D}$ values of different size fractions for Run HS4 are plotted along the flow direction, where $D$ is the sieve diameter. It can be observed in Fig. 11 that particles smaller than $0.028 \mathrm{~mm}$ do not have a peak value of $W_{D}$, which implies that particles smaller than $0.028 \mathrm{~mm}$ were carried further downstream in Run HS4.

In Table $2, D_{50}$ and geometric standard deviations, $\sigma_{g}$, of inflow and deposited sediment at different locations spaced 1 m apart are listed. Only Runs HS4, HK1, and TP2 were measured. Table 2 shows that the gradation of deposited sediment for Run HS4, with $\sigma_{g}$ around 1.60, is more uniform than that for an inflow gradation of 3.03. This is because that part of the inflow particles was too fine to deposit.

\section{Cohesive Sediment in Quasi-Homogeneous Flow}

In Table 2, $D_{50}$ values of the deposited sediment for Run HK1 were between 0.0051 and $0.0068 \mathrm{~mm}$. This slight dif- 
ference can be ignored because the particle sizes are so fine. This implies that the hydraulic sorting for cohesive sediment is insignificant. The $\sigma_{g}$ of Run HK1 is not presented here. Similar to $D_{50}, \sigma_{g}$ was about the same for all locations.

\section{Plunge Effect on Deposited Gradation}

The location of the plunge section of Run TP2 is between 7.4 and $8.6 \mathrm{~m}$ measured from the flume entrance, in which 7.4 $\mathrm{m}$ is the incipient plunge section and $8.6 \mathrm{~m}$ is the stable plunge section (Lee and Yu 1997). The record for $D_{50}$ of Run TP2 in Table 2 shows that hydraulic sorting plays a role within the measured reaches, and the sorting is stronger upstream than downstream of the plunge section. In Table 2 , the $D_{50}$ of the inflow sediment for Run TP2 is $0.02 \mathrm{~mm}$, which is a mixture of $20 \mathrm{~kg}$ of silica and $10 \mathrm{~kg}$ of kaolin. Comparison of $D_{50}$ between the inflow sediment and deposited sediment for Run TP2 shows that only silica powder $\left(D_{50}=0.052 \mathrm{~mm}\right)$ contributed to bed aggradation. The fine kaolin particles $\left(D_{50}=\right.$ $0.0068 \mathrm{~mm}$ ) with a dispersing agent were always kept suspended.

\section{CONCLUSIONS}

The main findings of the experiments with fine-sedimentladen flow entering a reservoirlike water body can be summarized as follows:

- The effective gravitational force is the main driving force for velocity in a stratified turbidity current. The velocity profile is closely related to the concentration profile.

- The local gradient Richardson number, $\mathrm{Ri}_{g}$, is larger than 0.25 in a deposition case. This indicates that the flow field near the interface in a deposition case is stable, and mixing can be ignored. The $\mathrm{Ri}_{g}$ value drops down to 0.17 around the interface in a nondeposition case in which the mixing is not negligible. The thickness calculated using the velocity profile is exactly the position where the $\mathrm{Ri}_{g}$ value is a minimum.

- The deposition rate of noncohesive coarse particles exponentially decays along the path for both quasi-homogeneous flow and stratified turbidity current. Most of the coarser particles were deposited in the quasi-homogeneous flow region or within a small distance downstream of the plunge section.

- Deposition in the turbidity current is primarily by fine cohesive particles for the studied cases.

- The deposition rate of fine cohesive particles increases along the flow direction in both a quasi-homogeneous flow and turbidity current. After the plunge section, however, the increase in the deposition rate slows down with distance.

- Hydraulic sorting exists in the quasi-homogeneous flow region for coarser noncohesive particles. Sorting becomes less significant in the region of weak-decay deposition rate.

- For cohesive fine particles, such as kaolin without dispersing agent, hydraulic sorting for the deposited gradation is not significant.

\section{ACKNOWLEDGMENT}

This study was supported by the National Science Council of the Republic of China under Grant No. NSC79-0410-E002-17.

\section{APPENDIX I. REFERENCES}

Altinakar, M. S., Graf, W. H., and Hopfinger, E. J. (1990). "Weakly depositing turbidity current on a small slope." J. Hydr. Res., Delft, The Netherlands, 28(1), 55-80.
Camp, T. R. (1946). "Sedimentation and the design of settling tanks." Trans. ASCE, 111, 895-936.

Ellison, T. H., and Turner, J. S. (1959). "Turbulent entrainment in stratified flows." J. Fluid Mech., Cambridge, U.K., 6, 423-448.

Fan, J., and Morris, G. L. (1992). "Reservoir sedimentation. I: Delta and density current deposits." J. Hydr. Engrg., ASCE, 118(3), 354-369.

Garcia, M. H. (1985). "Experimental study of turbidity currents." MS thesis, University of Minnesota, Minneapolis.

Garcia, M. H. (1993). "Hydraulic jumps in sediment-driven bottom currents." J. Hydr. Engrg., ASCE, 119(10), 1094-1117.

Lee, H. Y., and Yu, W. S. (1997). "Experimental study of reservoir turbidity current." J. Hydr. Engrg., ASCE, 123(6), 520-528.

Middleton, G. V. (1967). "Experiments on density and turbidity currents. III: Deposition of sediment." Can. J. Earth Sci., 4, 475-505.

Parker, G., Garcia, M., Fukushima, Y., and Yu, W. (1987). "Experiments on turbidity currents over an erodible bed." J. Hydr. Res., Delft, The Netherlands, 25(1), 123-147.

Sumer, M. S. (1977). "Settlement of solid particles in open channel flow." J. Hydr. Div., ASCE, 103(11), 1323-1337.

Turner, J. S. (1973). Buoyancy effects in fluids, Cambridge University Press, Cambridge, U.K.

Wunderlich, W. O., and Elder, R. A. (1973). "Mechanics of flow through man-made lakes." Man-made lakes: Their problems and environmental effects, C. Ackermann, G. F. White, and E. B. Worthington, eds., American Geophysical Union, Washington, D.C.

Yu, W. S., and Lee, H. Y. (1993). "Numerical simulation of turbidity current in reservoir." Int. J. Sediment Res., 8(2), 43-65.

Yu, W. S., Lee, H. Y., and Hsu, S. H. M. (2000). "Experimental study on delta formation in a reservoir." J. Chinese Inst. of Civ. and Hydr. Engrg., accepted for publication (in Chinese).

\section{APPENDIX II. NOTATION}

The following symbols are used in this paper:

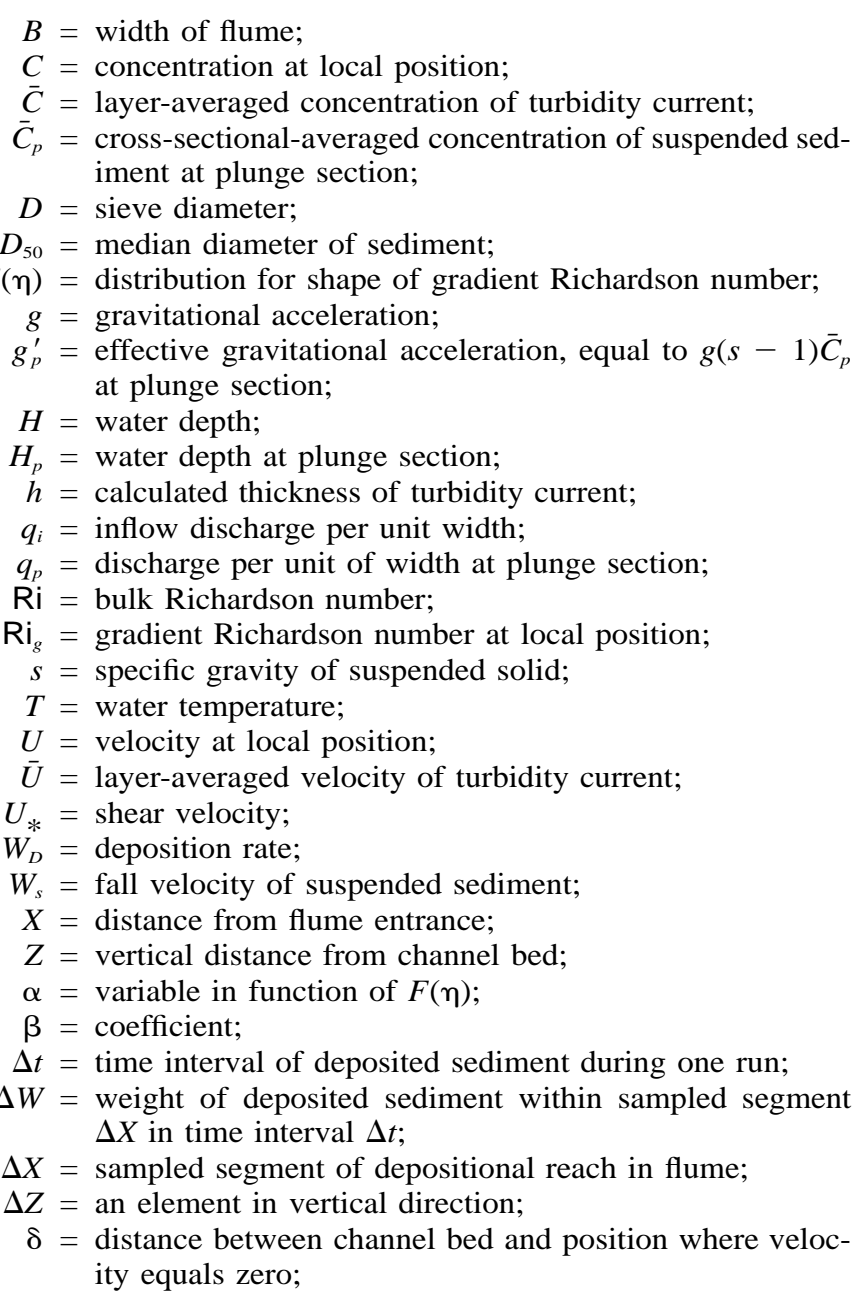


$\gamma_{s}=$ specific weight of sediment;

$\eta=Z / h$

$\theta=$ angle of bed slope;

$\kappa=$ von Kármán constant;

$\rho_{a}=$ density of ambient fluid;

$\rho_{m}=$ density of point inside turbidity current with specified $Z$ value; $\rho_{s}=$ density of suspended sediment; and

$\sigma_{g}=$ geometric standard deviations of deposited sediment.

\section{Subscripts}

$i=$ inflow; and

$p=$ plunge section. 